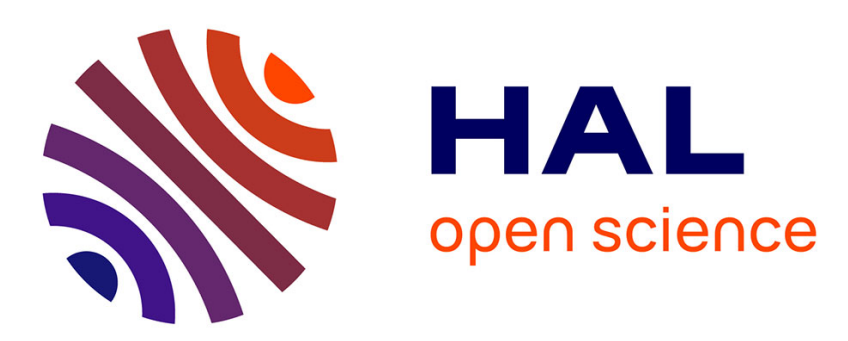

\title{
Unexpected Order-Disorder Transition in Diacetylene Alcohol Langmuir Films
}

Tomas Rego, Sylvie Spagnoli, Marie-Claude Fauré, Clémence Allain, Benoit Coasne, Jérémy Malinge, Chen Shen, Philippe Fontaine, Michel Goldmann

\section{- To cite this version:}

Tomas Rego, Sylvie Spagnoli, Marie-Claude Fauré, Clémence Allain, Benoit Coasne, et al.. Unexpected Order-Disorder Transition in Diacetylene Alcohol Langmuir Films. Langmuir, 2021, 37 (30), pp.9034-9042. 10.1021/acs.langmuir.1c01038 . hal-03357578

\author{
HAL Id: hal-03357578 \\ https://hal.science/hal-03357578
}

Submitted on 28 Sep 2021

HAL is a multi-disciplinary open access archive for the deposit and dissemination of scientific research documents, whether they are published or not. The documents may come from teaching and research institutions in France or abroad, or from public or private research centers.
L'archive ouverte pluridisciplinaire HAL, est destinée au dépôt et à la diffusion de documents scientifiques de niveau recherche, publiés ou non, émanant des établissements d'enseignement et de recherche français ou étrangers, des laboratoires publics ou privés. 


\section{Unexpected order-disorder transition in diacetylene alcohol Langmuir film}

Tomas Rego ${ }^{1}$, Sylvie Spagnoli ${ }^{2}$, Marie-Claude Faurél, ${ }^{3}$, Clémence Allain ${ }^{4}$, Benoit Coasne ${ }^{2}$, Jérémy Malinge ${ }^{4}$, Chen Shen ${ }^{5}$, Philippe Fontaine ${ }^{6,1}$, Michel Goldmann ${ }^{1,3,5 *}$

1. Institut des NanoSciences de Paris, UMR 7588 CNRS, Sorbonne Université, 4 place Jussieu, 75252 Paris CEDEX, France

2. LIPhy, CNRS, University Grenoble Alpes, Grenoble, France

3. UFR des Sciences Fondamentales et Biomédicales, Université de Paris, 45 rue des SaintsPères 75006 Paris CEDEX, France

4. Université Paris-Saclay, ENS Paris-Saclay, CNRS, PPSM, 91190, Gif-sur-Yvette, France.

5. DESY Photon Science, Notkestrasse 85, Hamburg D-22607, Germany

6. Synchrotron SOLEIL, L'Orme des Merisiers, Saint Aubin, BP48, 91192 Gif sur Yvette CEDEX, France

* Michel Goldmann 
KEYWORDS: Diacetylene alcohol, phase-transition, 2D organization, Langmuir monolayer

\section{- ABSTRACT}

The phase diagram of Langmuir film of diacetylene alcohol - henicosa-5,7-diyn-1-ol - is investigated by means of surface pressure versus surface area isotherms, Brewster Angle Microscopy (BAM), X-Ray Reflectivity (XRR) and Grazing Incident X-ray Diffraction (GIXD). Among the usual phases described in the generic phase diagram of small head group molecules, one observes an unexpected reversible transition from an ordered condensed phase to a disordered one upon increasing the surface pressure. We postulate that the origin of this unusual, unprecedented transition results from the competition between the interactions between the diacetylene blocks in the hydrophobic chain and the hydrogen bonds between head-groups and water.

\section{- INTRODUCTION}

Significant research activities are currently devoted to the development of biological and chemical sensors using molecular films made of diacetylene (DA) molecules which general formula is $\mathrm{R}-\mathrm{C} \equiv \mathrm{C}-\mathrm{C} \equiv \mathrm{C}-\mathrm{R}$ ' where $\mathrm{C} \equiv \mathrm{C}-\mathrm{C} \equiv \mathrm{C}$ is the diacetylene moiety and $\mathrm{R}$ and $\mathrm{R}$ ' are substituent groups. These materials can polymerize under irradiation in a topochemical way forming, usually, a blue polymer that can turn red using stimuli such as $\mathrm{pH}$, temperature, and solvent [1]. Their potential use in sensing applications was first explored in 1993 by Charych et al [2] where a polydiacetylene monolayer bearing special receptors at the end of side chains change from blue to red when incubated with biomolecules. Since then, increasing efforts have been made to design various sensing systems with polydiacetylene based materials [3], mainly on the synthesis of 
specific target-receptor couples derived from 10,12 pentacosadiynoic acid (PCDA). However, monolayer appears as more appropriate than bulk crystal to improve the signal/noise ratio when probing color changes. Considering this point, the Langmuir film procedure, made up of insoluble molecules adsorbed at the air/water interface, appears as an adapted study base since one can easily adjust the physico-chemical parameters (temperature, surface pressure) with the aim to understand the color transition.

Langmuir monolayer is an excellent model for studying two-dimensional systems. The study of insoluble fatty alcohols and acids on surface water leads to a generic phase diagram, which can be extended to various molecules by rescaling in function of the number of aliphatic carbon atoms [4, 5]. However, the rigidity of the diacetylene group prevents the use of such approach for amphiphilic DA molecules. As far as these complex compounds are concerned, only few data concerning the structure of PCDA have been published [6]. Among which an important result is that monolayer of PCDA at the air/water interface appears unstable with respect to the trilayer film, which prevents the formation of polymerized monolayer by UV irradiation [7]. To overcome this drawback, we propose to replace the acid headgroup by an alcohol. We synthetize a new DA molecule, henicosa-5,7-diyn-1-ol $(13-4 \mathrm{OH}),\left(\mathrm{CH}_{3}\left(\mathrm{CH}_{2}\right)_{12}-\mathrm{C} \equiv \mathrm{C}-\mathrm{C} \equiv \mathrm{C}-\left(\mathrm{CH}_{2}\right)_{3}-\mathrm{CH}_{2} \mathrm{OH}\right)$ with 13 saturated carbons followed by the DA group in the hydrophobic chain. We determine the phase diagram of 13-4OH Langmuir monolayers at the air/water interface, by surface pressure versus surface area isotherms, Brewster Angle Microscopy (BAM), X-Ray Reflectivity (XRR) and Grazing Incidence X-ray Diffraction (GIXD) experiments. The structure of the organized phase was also probed by molecular dynamics approach. Among the expected 2D gas (G), liquid expanded (LE) and liquid condensed (LC) phases, one observes that 13-4OH molecules undergo an unexpected reversible phase transition from an ordered LC phase to a disordered phase as the 
surface pressure increases. Comparison with henicosa-5,7-diynoic acid (13-3COOH), an analogous molecule to $13-4 \mathrm{OH}$ suggests that this transition is related to specific intermolecular interactions in $13-4 \mathrm{OH}$ monolayer at the air/water interface.

\section{- MATERIALS AND METHODS}

Synthesis of henicosa-5,7-diyn-1-ol (13-4OH). $\mathrm{n}-\mathrm{BuNH}_{2}(2.5 \mathrm{~mL}, 25.4 \mathrm{mmol})$, distilled water $(13 \mathrm{~mL})$ and $\mathrm{CH}_{2} \mathrm{Cl}_{2}(13 \mathrm{~mL})$ were successively added to a round bottom flask containing $\mathrm{CuCl}$ $(0.10 \mathrm{~g}, 1.0 \mathrm{mmol})$. The resulting mixture was vigorously stirred and cooled to $0^{\circ} \mathrm{C}$. A few crystals of hydroxylamine were used to discharge the blue color and pentadecyne $(0.7 \mathrm{~mL}, 2.54 \mathrm{mmol})$ was slowly added at $0^{\circ} \mathrm{C}$. The mixture turned bright yellow. After 5 min at $0^{\circ} \mathrm{C}$, a solution of 6 bromohex-5-yn-1-ol (prepared as described in [8]) $(0.45 \mathrm{~g}, 2.54 \mathrm{mmol})$ in $\mathrm{CH}_{2} \mathrm{Cl}_{2}(5 \mathrm{~mL})$ was slowly added. Few crystals of hydroxylamine may be needed to prevent the reaction from turning green. Once the addition completed, the reaction mixture was stirred 20 min at $0^{\circ} \mathrm{C}$ and was warmed up to room temperature over $90 \mathrm{~min}$. The resulting pale green solution was extracted with $\mathrm{CH}_{2} \mathrm{Cl}_{2}$. The combined organic layers were washed with a saturated aqueous ammonium chloride solution, dried over $\mathrm{MgSO}_{4}$ and concentrated in vacuo. The residue was then purified over silica (20\% EtOAc in petroleum ether) providing a white solid which should be cautiously protected from light because of efficient polymerization in the powder state $(0.55 \mathrm{~g}, 71 \%$ yield $)$. The synthesis has been summarized in Scheme S1. ${ }^{1} \mathrm{H}$ NMR $\left(400 \mathrm{MHz}, \mathrm{CDCl}_{3}\right): \delta=3.63(\mathrm{t}, J=6.0 \mathrm{~Hz}$, 2H), $2.31(\mathrm{t}, J=6.4 \mathrm{~Hz}, 2 \mathrm{H}), 2.22(\mathrm{t}, J=7.3 \mathrm{~Hz}, 2 \mathrm{H}), 1.86(\mathrm{bs}, 1 \mathrm{H}), 1.63(\mathrm{~m}, 4 \mathrm{H}), 1.48(\mathrm{~m}, 2 \mathrm{H})$, 1.23 (bs, 20H), 0.86 (t, $J=6.4 \mathrm{~Hz}, 3 \mathrm{H}) .{ }^{13} \mathrm{C}$ NMR (100 MHz, CDCl3): $\delta=78.0,65.8,65.2,62.5$, $32.1,31.9,29.82,29.79,29.76,29.6,29.5,29.3,29.0,28.5,27.1,24.1,22.8,19.3,19.1,14.3$ ppm.

Synthesis of henicosa-5,7-diynoic acid (13-3COOH). 13-3COOH was synthesized from 5hexynoic acid and 1-bromopentadecyne (prepared by bromination of commercial 1-pentadecyne 
by $\mathrm{N}$-bromosuccinimide in acetone in the presence of a catalytic amount of silver nitrate) following the procedure described in [9].

${ }^{1} \mathrm{H}-\mathrm{NMR}\left(400 \mathrm{MHz}, \mathrm{CDCl}_{3}\right) \delta 2.51(\mathrm{t}, J=7.6 \mathrm{~Hz}, 2 \mathrm{H}), 2.36(\mathrm{t}, J=7.0 \mathrm{~Hz}, 2 \mathrm{H}), 2.24(\mathrm{t}, J=7.2$, 2H), $1.86(\mathrm{tt}, J=7.0 \mathrm{~Hz}, J=7.6 \mathrm{~Hz}, 2 \mathrm{H}), 1.52(\mathrm{tt}, J=7.0 \mathrm{~Hz}, J=7.6 \mathrm{~Hz}, 2 \mathrm{H}), 1.39-1.32(\mathrm{~m}, 2 \mathrm{H})$, $1.26(\mathrm{~m}, 18 \mathrm{H}), 0.88(\mathrm{t}, J=6.9 \mathrm{~Hz}, 3 \mathrm{H}) .{ }^{13} \mathrm{C}-\mathrm{NMR}\left(75.5 \mathrm{MHz}, \mathrm{CDCl}_{3}\right) \delta 178.1,78.3,75.8,66.5$, $65.1,32.5,32.1,29.8(4 \mathrm{C}), 29.6,29.5,29.2,29.0,28.4,23.4,22.9,19.3,18.71,14.3$

$\pi$-A Isotherms. The molecules were dissolved in chloroform to obtain a spreading solution of typical concentration of $1 \mathrm{mmol} / \mathrm{L}$. Monolayers were spread on a Langmuir trough equipped with two movable barriers and the surface pressure $(\pi)$ was measured using the Wilhelmy plate method. The plate was made with filter paper, and the measurement device was a microbalance from Riegler \& Kirstein GmbH (Germany). Milli-Q Millipore ultrapure water was used for the subphase (MilliQ R $\geq 18 \mathrm{M} \Omega \mathrm{cm}$ ). Temperature was regulated at $+/-0.5^{\circ} \mathrm{C}$ using a circulating water bath. The surface pressure balance was calibrated with the value of surface tension of pure water for each temperature. The solution was spread at the air/water interface by drop-wise addition and allowed to equilibrate for 20 min to ensure evaporation of organic solvent. Surface pressure vs. area per molecule $(\pi-\mathrm{A})$ isotherms were measured by continuously moving the barrier compressing the layer with a linear speed of $0.23 \mathrm{~cm}^{2} \mathrm{~s}^{-1}\left(1.210^{-4} \mathrm{~nm}^{2}\right.$ molecule $\left.\mathrm{e}^{-1} \mathrm{~s}^{-1}\right)$. The stability of the $13-4 \mathrm{OH}$ monolayer has been tested at different temperatures during two hours for various surface pressures. The film is stable as a monolayer, since no pressure drift occurs at any of the pressures used in this study.

The compressibility of the phases is computed using the following definition:

$$
\chi=-\frac{1}{A} \frac{d A}{d \pi}
$$


where $A$ and $\frac{d A}{d \pi}$ are determined by numerical derivative of the experimental $\pi$-A isotherm for the macroscopic compressibility and from the unit cell area deduced by GIXD for the microscopic compressibility.

Brewster Angle Microscopy (BAM). We used a homemade BAM with a laser wavelength at $532 \mathrm{~nm}$ and a power of $100 \mathrm{~mW}$ (CNI MGL-III-532). The angle between the beam and the normal to the interface was adjusted to $53.1^{\circ}$, the Brewster angle of the air/water interface. Pictures of the monolayer were captured thanks to a CCD camera (Watec: WAT-902H-Ultimate) used in automatic gain control. The image size is $425 \mu \mathrm{m} \times 410 \mu \mathrm{m}$ and due to the tilt between the water surface and the optical axis, only a stripe of about $20 \mu \mathrm{m}$ is in focus. The surface pressure was measured using a Wilhelmy plate made of calibrated filter paper.

Reflectivity (XRR). X-ray Reflectivity (XRR) measurements were performed using the LISA diffractometer [10] on the P08 beamline [11] at PETRA III. The incident x-ray beam energy was $18 \mathrm{KeV}$ and the Langmuir trough was enclosed in a sealed chamber flushed with helium. The reflected photons were measured by a 2D detector (Lambda 750K GaAs, X-Spectrum, Germany) allowing to subtract the background from the diffuse scattering measured in the plane of incidence. At each angle, the reflected intensity is normalized to the incident beam intensity. Thereafter, the reflectivity curve is normalized by the intensity value at the critical angle. Spectra analysis was performed with the interdif module of GenX [12].

Grazing Incidence X-ray Diffraction (GIXD). Grazing Incidence X-ray Diffraction (GIXD) experiments were carried out at the SIRUS beamline at SOLEIL synchrotron. Details of the beamline optics can be found in the literature [13]. The incident $\mathrm{x}$-ray beam energy was $8 \mathrm{keV}(\lambda$ $=0.155 \mathrm{~nm})$. Beam size $(\mathrm{V} \times \mathrm{H})$ was $0.1 \times 0.5 \mathrm{~mm}^{2}$. A custom-built Langmuir trough was enclosed in a temperature controlled sealed chamber and flushed with helium during data collection. The 
water surface was illuminated at an incident angle of $2 \mathrm{mrad}$ below the critical angle $(2.7 \mathrm{mrad})$ of the air-water interface so that the incident wave was almost totally reflected. In this regime the refracted wave is evanescent, probing the interface with a penetration depth of a few nanometers. The scattered signal was measured by a vertical 1D low noise position sensitive detector of 150 $\mathrm{mm}$ height associated with a Soller collimator.

The diffraction peaks were fitted with a Lorentzian shape to extract the in plane peak position (Qhk), Full Width at Half Maximum (FWHM), and intensity (I). The positional correlation length $\xi$ was obtained from the full width at half maximum FWHM using $\xi=2 /$ FWHM. The error associated with the lattice parameters is lower than $0.1 \mathrm{~nm}$ and estimated at $1 \mathrm{~nm}$ for $\xi$. Along the $z$ direction (perpendicular to the air/water interface) spectra were fitted with a squared Cardinal Sinus function to determine the $\mathrm{Q}_{z}$ position of the maximum intensity. Details on the analysis of the GIXD data can be found in the literature $[4,14]$.

Molecular simulation. Molecular dynamics (MD) simulations of a 13-4OH monolayer on water were performed with LAMMPS [15]. The simulation box contains a slab of about 11000 water molecules in contact with vacuum on one side and with the hydroxyl end of a monolayer with 162 alcohol molecules on the other side (corresponding to a rectangular box with $9 \times 9$ unit cells as determined in the experiments). The ends of the alkyl chains of the alcohols are also exposed to vacuum. The equations of motion are integrated with the velocity Verlet algorithm using a time step of 5 fs. Periodic boundary conditions (PBC) were used in the three directions of space. The temperature is controlled using a Nose-Hoover thermostat with a time constant of $0.05 \mathrm{ps}$. Water is modeled using the SPC/E water model $[16,17]$. The $\mathrm{CH}_{3}, \mathrm{CH}_{2}, \mathrm{CH}, \mathrm{C} \equiv \mathrm{C}$ and $\mathrm{OH}$ groups are modeled with the Lennard-Jones interactions from the all-atom OPLS force field [18]. 
We conducted simulations in the NVT ensemble in which the lattice parameters were imposed $(\mathrm{a}=0.57 \mathrm{~nm}$ et $\mathrm{b}=0.901 \mathrm{~nm})$. To constrain the system to remain in a state compatible with the experimental data, the alcohol head groups (O atom) were fixed at the corresponding crystallographic data. The system was first equilibrated at $285 \mathrm{~K}$ in the NVT ensemble prior to a production run that lasted at least a few ns (it was checked that longer production times do not alter the results). The diffraction pattern was determined by calculating the square of the Fourier transform of the electron density $\rho(x, y) . \rho(x, y)$ is the integrated electronic density along the $\mathrm{z}$ axis taking all the atoms into account and averaged on the last twenty configurations.

\section{- RESULTS AND DISCUSSION}

$\pi$-A Isotherms. Figure 1 presents the $\pi$-A isotherms of $13-4 \mathrm{OH}$ between $12^{\circ} \mathrm{C}$ and $28^{\circ} \mathrm{C}$. The values (lift-off, surface pressure of phase transitions) measured from these curves are presented in table 1 . Below $16^{\circ} \mathrm{C}$, a direct gas $(\mathrm{G})$ to liquid condensed (LC1) transition is observed with a collapse pressure at about $30 \mathrm{mNm}^{-1}$. The liquid expanded (LE) phase is observed at $16^{\circ} \mathrm{C}$ and above. The macroscopic compressibility of the LE and LC1 phases are $\chi=37 \pm 3 \mathrm{mN}^{-1}$ and $\chi=10 \pm 5 \mathrm{mN}^{-1}$, respectively, in the range of LE and LC phase of fatty acids or alcohols [19,20]. In the $12-18^{\circ} \mathrm{C}$ temperatures range, a careful analysis of the $\pi-\mathrm{A}$ isotherms (Figure S6b) evidences the presence of a small plateau at high surface pressure indicating a phase transition between the called LC1 phase and a less compressible phase labelled LC2. Its compressibility value was determined between $5<\chi<8 \mathrm{mN}^{-1}$. The surface pressure plateau value, $\pi_{\mathrm{LC} 1-\mathrm{LC} 2}$, remains stable even when the compression barrier speed is doubled or halved. Moreover, it is reproducible along compression-expansion before the collapse of the monolayer (Figure S2). 
Upon compressing the film above the collapse surface pressure, a plateau at about $30 \mathrm{mNm}^{-1}$ is observed which extends up to about $0.08 \mathrm{~nm}^{2} /$ molecule (Figure S3). The latter could be attributed to a transition from monolayer to a triple layer. Although an hysteresis is observed upon expansion/compression cycles (Figure S3) the compression/expansion cycles are reproducible which indicate that the film re-spreads as a monolayer, in stark contrast to the behavior of a film of PCDA molecules [7].

The phase diagram deduced from the isotherm data is presented on Figure 2. The LE-LC phase transition behaves as expected (LC means a Liquid Condense phase whatever its nature LC1 or LC2). The two-dimensional analogue of the Clausius-Clapeyron equation may be written as:

$$
\Delta H=T\left(A_{L E}-A_{L C}\right) \frac{d \pi_{L E-L C}}{d T}=T \Delta A \frac{d \pi_{L E-L C}}{d T}
$$

where $\pi_{\mathrm{LE}-\mathrm{LC}}$ is the value of the LE-LC pressure of the phase transition plateau and ALE and ALC the molar areas at the corresponding transition temperature T (Figure S4). The subscripts LE and LC refer to the liquid expanded and liquid condensed states respectively (both LC1and LC2). Assuming a linear variation of $\pi_{\mathrm{LE}-\mathrm{LC}}$ with temperature, one obtains a coefficient $\mathrm{d} \pi_{\mathrm{LE}-\mathrm{LC}} / \mathrm{dT}=1.8$ $\mathrm{mNm}^{-1} \mathrm{~K}^{-1}$. The calculated enthalpies versus temperature are given in Table $\mathrm{S} 6 . \Delta \mathrm{H}$ decreases linearly with temperature leading to a critical temperature of about $27-28^{\circ} \mathrm{C}$ (Figure S5), in agreement with the isotherms on Figure 1.

However, one notes on Figure 2 that the LC1-LC2 transition presents an unusual behavior as $\pi_{\mathrm{LC} 1-}$ LC2 decreases upon increasing the temperature. Assuming a linear variation of $\pi_{\mathrm{LC1}-\mathrm{LC} 2}$ with temperature, one obtains a coefficient $\mathrm{d} \pi_{\mathrm{LCl}-\mathrm{LC} 2} / \mathrm{dT}=-2 \mathrm{mNm}^{-1} \mathrm{~K}^{-1}$. The enthalpy variation for this endothermic transition is calculated as above with $\Delta H=T\left(A_{L C 1}-A_{L C 2}\right) \frac{d \pi_{L C 1-L C 2}}{d T}$. The 
results are presented Table S7. The enthalpy variation for the LC1-LC2 transition is one order of magnitude lower than the one for the LE-LC transition.

Brewster Angle Microscopy. Figure 3 presents Brewster Angle Microscopy (BAM) images as recorded during compression at $\mathrm{T}=13 \pm 0.5^{\circ} \mathrm{C}$. This temperature was chosen below the triple point so the LE phase is not observed. Up to $15 \mathrm{mNm}^{-1}$ (Figure 3a-c), one observes LC1 domains coexisting with the $\mathrm{G}$ phase. These domains present a curved shape suggesting a rather small line tension value. When the surface pressure reaches $24 \mathrm{mNm}^{-1}$, which corresponds to the transition between the two LC phases detected by the isotherms, the large LC1 domains split into smaller domains as shown on Figure 3d. One can see on this figure that the reflected intensity is similar for the two types of domains, which indicates a negligible variation of the optical index of the two domain types and, hence, a constant thickness and density.

X-ray reflectivity. X-ray reflectivity (XRR) of $13-4 \mathrm{OH}$ monolayer were performed at $14 \pm 0.5^{\circ} \mathrm{C}$ upon compression and expansion. A single layer model did not allow for a reasonable adjustment of the reflectivity spectra. Consequently, a two-layers model was used, labeled bottom and top layers for the one in contact with the water subphase and the one in contact with air, respectively. The resulting fitted parameters are presented in Table 2 and the variation of the thicknesses versus surface pressure in Figure 4. Attempts in adjusting the spectra with a three layers model lead to unsatisfactory results since the intermediate layer thickness associated with the diacetylene group is always thinner that its roughness. The reflectivity spectra and adjustments with the two-layer model are presented in Figure S8. Even if the total thickness of the film remains constant at about $1.7 \mathrm{~nm}$, one observes a variation of the thickness of each layer for surface 
pressure varying between 18 and $22 \mathrm{mN} \cdot \mathrm{m}^{-1}$ (Figure 4). This result is thought to be a signature of the transition between the two LC phases. Assuming an all-trans carbon chain that can be described as a rod with a length of $2.45 \mathrm{~nm}$, one obtains a tilt angle of $45^{\circ}$, in the range of the one measured by GIXD (see next paragraph). This suggest that the measured thickness is associated to the chain indicating that the contrast between the average densities of the water subphase and the one of the hydrophilic group region remains weak. These results appear reversible upon expansion. Reflectivity experiments on polymerized monolayer formed by molecules wearing two diacetylene chains with a bulky headgroup has been fitted with three layers (one representing this hydrophilic head group) [21]. A four-layer model has been used only when the film was polymerized. Our two layers model is in the same category since $13-4 \mathrm{OH}$ wears a small hydrophilic headgroup and the monolayer is not polymerized.

Grazing Incidence X-ray Diffraction. 13-4OH Langmuir films were further investigated at the air/water interface using in situ synchrotron grazing incidence x-ray diffraction (GIXD). We notice that $13-4 \mathrm{OH}$ monolayer is not reactive under $\mathrm{x}$-ray nor UV irradiations. Figure 5 presents the diffraction profiles obtained at $12^{\circ} \mathrm{C}$ for $\pi=1,5,10,15,20$ and $25 \mathrm{mNm}^{-1}$. The corresponding integrated scattered intensity along $\mathrm{Q}_{z}$ with respect to $\mathrm{Q}_{\mathrm{xy}}$ are presented in Figure S9. Peak parameters extracted through fits of the experimental curves are gathered in Table 3. At low surface pressure $\left(1 \mathrm{mNm}^{-1}\right), 13-4 \mathrm{OH}$ monolayer exhibits two diffraction peaks: one at $\mathrm{Q}_{\mathrm{xy}}=12.82 \mathrm{~nm}^{-1}$ and with a maximum intensity at $\mathrm{Q}_{z}=9.32 \mathrm{~nm}^{-1}$ (out of plane) and one at $\mathrm{Q}_{\mathrm{xy}}=13.86 \mathrm{~nm}^{-1}$ with a maximum intensity in the plane. The FWHM of their rodscan along Qz range between 1,8 $\mathrm{nm}^{-1}$ and $1 \mathrm{~nm}^{-1}$ which indicates that the thickness of the corresponding diffracting plane remains to the order of the one of the monolayer (figure S9). These peaks can be indexed as $[-1,1]$ and $[0,2]$ 
respectively by using a rectangular unit cell which parameters for the various surface pressure are presented in Table S10. The configuration of the $[-1,1]$ and $[0,2]$ peaks indicates a Next Neighbor (NN) tilt of the chains with a tilt value around 40 degrees as reported in Table S10, of the same order of magnitude to the one deduced from XRR (45 degrees). Upon compression, both peaks shift to higher $\mathrm{Q}_{\mathrm{xy}}$ as the out-of-plane $\mathrm{Q}_{z}$ maximum of the $[-1,1]$ peak decreases, indicating a gentle decrease of the tilt angle. A microscopic compressibility can be determined from the area of the rectangular unit cell and one obtains $\chi_{\mathrm{m}}=2.4 \mathrm{~m} / \mathrm{N}$, in agreement with the value expected for a $\mathrm{LC}$ phase [20]. One notice (Table S10) that only the a parameter is varying with $\pi$, evidencing that the compressibility is almost zero along the $\mathbf{b}$ direction, which is compatible with a tilt along the $\mathbf{a}$ direction. It can be also noticed that the coherence length is 6 times larger along the $\mathbf{b}$ direction than along the a direction. Such an anisotropy has been observed in long fatty acids [20], long fatty alcohols at zero pressure [22] and in amphiphilic alcohols [23]. However, the most striking result is that at higher pressures the diffraction peaks vanish when the surface pressure increases as shown on Figure 5.

Contrary to the XRR measurements, the transition between LC1 and LC2 phases is clearly detected by GIXD. Upon compression, one observes a decrease of the intensities at the transition (Figure 5). Simultaneously, the coherence length of the $[-1,1]$ peak remains almost constant up to $15 \mathrm{mNm}^{-1}$, and strongly decreases upon further compression as the coherence length of the $[0,2]$ peak decreases continuously when the surface pressure increases (Table 3). This clearly, although surprisingly, indicates a transition to a disordered phase. One cannot link this change to a precollapse kinetic effect as it happens at a surface pressure far below the collapse pressure, $5 \mathrm{mNm}^{-}$ ${ }^{1}$ below the collapse at $12^{\circ} \mathrm{C}$ and up to $20 \mathrm{mNm}^{-1}$ below the collapse at $18^{\circ} \mathrm{C}$. Moreover, XRR indicates that the film remains as a monolayer (constant layer thickness with surface roughness 
remaining in the same range). In addition, the isotherms (Figure S2) and the diffraction spectra (Figure 6) are reversible, which is not the case when the film collapse. The loss of signal starts by a broadening of the $[0,2]$ peak, but the symmetry of the remaining in plane unit cell remains unchanged. Then, at a surface pressure corresponding to $\pi_{\mathrm{LC} 1-\mathrm{LC} 2}($ second plateau of the isotherm), the signal vanishes completely indicating that $13-4 \mathrm{OH}$ monolayer undergoes a reversible loss of positional order under compression before collapse. This behavior is not usual as one expects a better order when the pressure is increased.

Molecular arrangement. Due to the limited diffraction peaks observed and the various possibilities for the chain configuration in the LC1 phase (induced by the possible rotation of the rigid diacetylene block), the diffraction data do not allow in deducing the conformation of the molecule in this structured phase. To shed some light into the molecular conformation of the 13$4 \mathrm{OH}$ chains, we performed a simple molecular dynamics (MD) approach. While an in-depth molecular simulation strategy is out of the scope of the present paper, the approach below aims in providing a simple tool to extract refined structural/conformational information from available experimental data. In practice, we built a molecular configuration consisting of a single monolayer adsorbed on the water subphase while constraining simple parameters (namely, the lattice parameter/symmetry) to their value inferred from the x-ray analysis. The schemes S11 and S12 give the labeled carbon atoms of $13-4 \mathrm{OH}$ and its orientation. The simulations are performed at a temperature $\mathrm{T}=12^{\circ} \mathrm{C}$ where the monolayer is in the $\mathrm{LC} 1$ phase. To build a system as close as possible to the experimental one, the oxygen atoms of the alcohol headgroup has been settled to fixed positions corresponding to the experimentally observed structure. All the rest of the system (DA chains and water molecules) is free to relax. 
The simulation leads to conformations in which the DA molecules are tilted by $44^{\circ}$ along the $a$ direction. Table S13 summarizes the values of the different orientational angles calculated. Such configuration is compatible with the experimental results, suggesting that our simple molecular simulations capture this important structural feature. The thickness of the two distinct slices formed by (1) $\mathrm{C} \equiv \mathrm{C}-\mathrm{C} \equiv \mathrm{C}-\left(\mathrm{CH}_{2}\right)_{3}-\mathrm{CH}_{2} \mathrm{OH}$ DA+head group) and (2) the saturated alkyl chain $\left(\mathrm{CH}_{3}\left(\mathrm{CH}_{2}\right)_{12}-\right)$ were analyzed. Thicknesses of $0.827 \mathrm{~nm}$ and $1.14 \mathrm{~nm}$ were obtained for the DAthead group and the alkyl chain, respectively. These values are reasonably close to the ones obtained by means of XRR experiments $(0.742 \mathrm{~nm}$ and $1.12 \mathrm{~nm}$, respectively). The diffraction pattern calculated from the simulated configurations is presented in Figure S14. There is also a reasonable agreement for both the $[0,2]$ and $[-1,1]$ peaks which are localized at $Q_{x y}=14 \mathrm{~nm}^{-1}$ and $Q_{x y}=13.3 \mathrm{~nm}^{-1}$ from the simulations as they are experimentally measured at $Q_{x y}=13.94 \mathrm{~nm}^{-1}$ and $\mathrm{Q}_{\mathrm{xy}}=13.1 \mathrm{~nm}^{-1}$ at $15 \mathrm{mNm}^{-1}$. The poorer agreement for the $[-1,1]$ peak can be justified by the fact that, despite the presence of the di-acetylene groups the alkyl-alkyl interactions are considered as correctly treated by the OPLS force field (similar simulations performed on fatty alcohols are in good agreement with experimental data [24]). Therefore, considering that the molecular mechanics approach reported in the present paper correctly describes the tilt angle and direction, we conclude that the small discrepancy between the simulated and experimental diffraction spectrum results from a less accurate force field description of the interactions between the DA group of the molecules.

Analogous DA acid 13-3COOH. In order to determine the influence of the head group interaction with respect to the DA interactions, we synthesized the fatty acid $\mathrm{CH}_{3}-\left(\mathrm{CH}_{2}\right)_{11}-\mathrm{CH}_{2}-$ $\mathrm{C} \equiv \mathrm{C}-\mathrm{C} \equiv \mathrm{C}-\left(\mathrm{CH}_{2}\right)_{3}-\mathrm{COOH}(13-3 \mathrm{COOH})$ which has the same hydrophobic chain with 13 saturated 
carbons. It appears then as analog to $13-4 \mathrm{OH}$, but with a carboxylic acid head group. We probe the monolayer phase diagram by compression isotherms at temperatures between $10^{\circ} \mathrm{C}$ and $25^{\circ} \mathrm{C}$ (Figure S15), as well by BAM (Figure S16) and GIXD (Figure S17) experiments. As expected, the collapse occurs at a lower surface-pressure than the one observed for $13-4 \mathrm{OH}$. More importantly, no signature of a transition between two LC phases can be detected, neither by isotherms nor by BAM experiments. GIXD measurements indicate a continuous growth of the peaks when the surface pressure increases with only a slight increase of the FWHM of the $[-1,1]$ peak leading to coherence length ranging between $40 \mathrm{~nm}$ to $30 \mathrm{~nm}$. Such a result compared to the ones obtained with 13-4OH suggests that both the DA-DA interactions and the alcohol head group interactions are involved in this order-disorder phase transition. This evidences the importance of the alcoholic head group in the LC phases, although it is considered a "small head".

Discussion. The study of fatty alcohol and fatty acid monolayers at the air/water interface leads to a generic phase diagram which is normalized by the number of aliphatic carbon atoms [4, 5]. This generic phase diagram is mainly based on the chain interactions as the hydrophilic head interactions appear as negligible (small hydrophilic head approximation). This was expected for $13-4 \mathrm{OH}$ but the presence of the rigid 6 carbons of the DA group $\mathrm{CH}_{2}-\mathrm{C} \equiv \mathrm{C}-\mathrm{C} \equiv \mathrm{C}-\mathrm{CH}_{2}$ in the hydrophobic chain modifies the entropy of the chain configuration which is one of the parameters determining the LE-LC transition. Considering the thermodynamic behavior of the LE-LC transition, we deduced that $13-4 \mathrm{OH}$ is equivalent to a $\mathrm{C} 15$ aliphatic chain if one considers the Figure $3 b$ of reference [4]). In the LE phase, the interactions between DA groups are rather weak and the transition to the LC phase appears at least mainly driven by the alkyl chains interactions with respect to their possible configurations. 
This entropy term almost disappears in the LC phase in which it is however reasonable to consider that the DA-DA interactions are no longer negligible and probably also those between the hydrophilic head groups. We believe that these interactions are related to the origin of the unexpected order-disorder transition observed in the 13-4OH monolayer when the surface pressure increases. Indeed, an hypothesis based on the breaking of an H-bond network in the polar head region competing with the DA-DA interactions cannot be excluded to explain this transition. It is, to our knowledge, the first observation of such a transition in Langmuir monolayers. However, a partial loss of positional correlation has been observed under pressure increase in mono and bipolar docosanol derivatives [25] or in octadecylurea [26]. Majewski et al [22] have shown that alcohols monolayer can induce the nucleation of ice due to $\mathrm{H}$-bonds between water molecules and $\mathrm{OH}$ group of the amphiphilic molecule. Moreover, the presence of an ice-like structure at the water surface covered by octadecanol monolayer was observed via IR spectroscopy of the OH group [27]. An area contraction upon temperature increase at constant pressure has been observed on monolayer with urea headgroups and was explained by an hydrogen-bond network formed between the urea headgroups [25]. In 13-4OH monolayer, the smallest distance between two oxygen atoms is $0.538 \mathrm{~nm}$ at $\pi=5 \mathrm{mNm}^{-1}$ and $0.530 \mathrm{~nm}$ at $\pi=20 \mathrm{mNm}^{-1}$. Despite this rather large distance the range of the enthalpy variation, $\Delta \mathrm{H}=-1 \mathrm{~kJ} / \mathrm{mol}$, is of the same order of magnitude of the endothermic transition in docosanol $\Delta \mathrm{H}=0.428 \mathrm{~kJ} / \mathrm{mol}$ at $30^{\circ} \mathrm{C}$ and $0.844 \mathrm{~kJ} / \mathrm{mol}$ at $35^{\circ} \mathrm{C}[25]$.

The properties of $13-4 \mathrm{OH}$ can be summarized as follows. The experimental results show that under compression, the monolayer undergoes a LE-ordered LC1 then an ordered LC1-disordered LC2 phase transitions. However, the LC1-LC2 phase transition is not observed in the analogous fatty acid $13-3 \mathrm{COOH}$, which indicates that the $\mathrm{OH}$ head group is involved in this transition. The 
disorder could then result from a competition between DA-DA interactions and $\mathrm{OH}-\mathrm{OH}$ and/or $\mathrm{OH}-\mathrm{H}_{2} \mathrm{O}$ interactions when the pressure increases. At least two hypotheses can be proposed. In the first one, an hydrogen bond network appears between $\mathrm{OH}$ head group and water in the $\mathrm{LC} 1$ phase. This hydrogen bond network should be weak since the unit cell parameters are large compared to those involving the usual H-bond length. The transition LC1-LC2 would then result from the breaking of this network. In the second one, on the contrary, the probability to form H-bond increases when the pressure increases leading to the disordered structure due to the competition with the LC1 structure resulting from aliphatic chains and DA interactions. The knowledge of the atomic conformation of the molecule would be of great help to understand this transition.

\section{- CONCLUSION}

We synthesized a DA-OH molecule, 13-4OH, whose hydrophilic headgroup leads to stable monolayer in contrast to DA-COOH in which the trilayer structure appears stable with respect to the monolayer. This is an important feature for the future use of these systems as key ingredient in sensors. The thermodynamic analysis indicates that the DA group can be considered as equivalent to one $\mathrm{CH}_{2}$ in the LE phase. However, one observes that, besides the expected LE-LC transition, 13-4OH monolayer exhibits an unusual order-disorder transition between two LC phases as the surface pressure increases. It is reasonable to consider that the driving force of the order-disorder transition results from the competition between this DA-DA interaction and the interactions involved in the hydrophilic layer. 

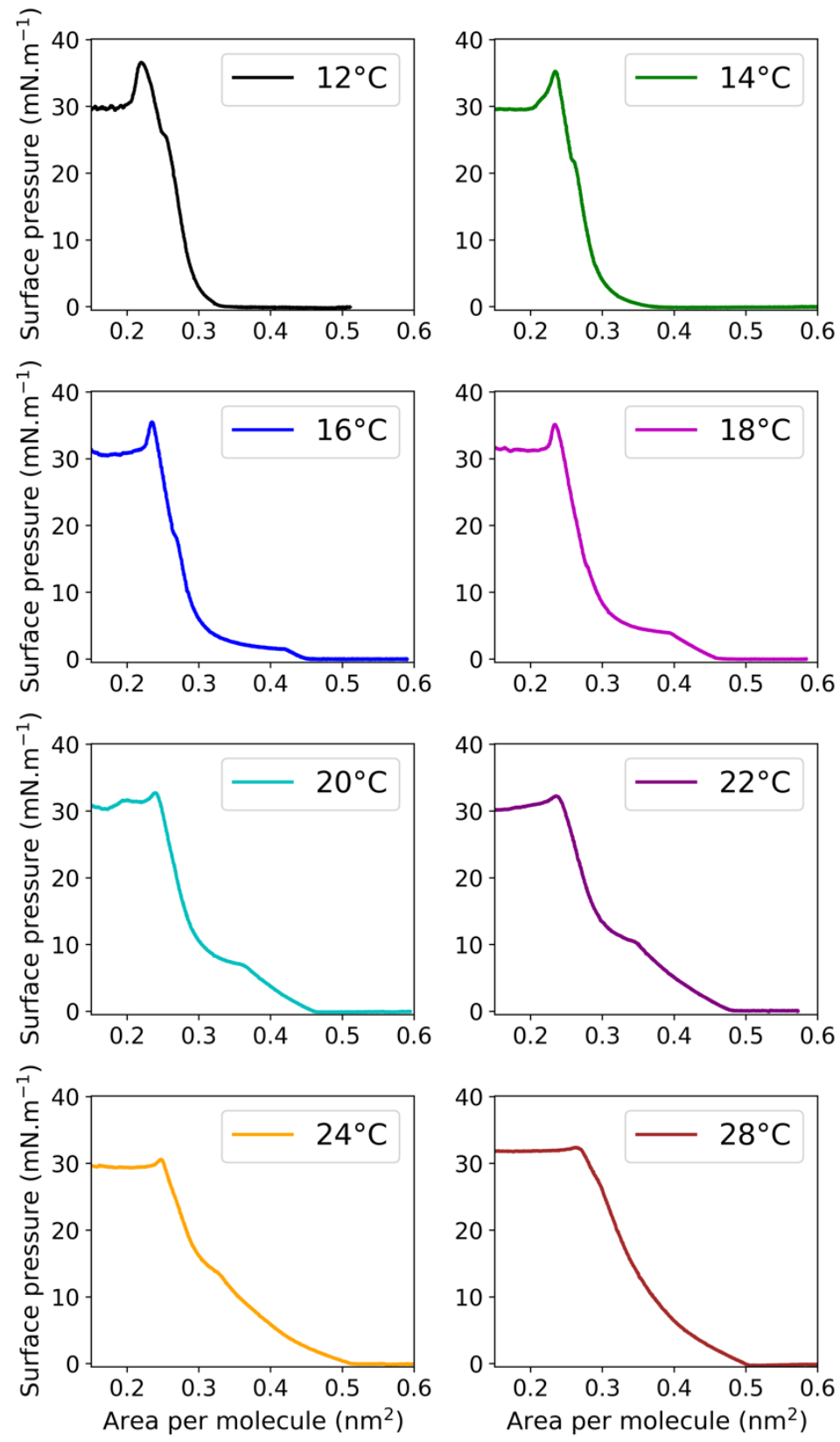

Figure 1: $13-4 \mathrm{OH} \pi$-A isotherms at different temperatures between $12^{\circ} \mathrm{C}$ and $28^{\circ} \mathrm{C}$ 


\begin{tabular}{|c|c|c|c|c|c|c|c|c|}
\hline Temperature $\left({ }^{\circ} \mathrm{C}\right)$ & 12 & 14 & 16 & 18 & 20 & 22 & 24 & 28 \\
\hline $\begin{array}{l}\text { Lift-off } \\
\left(\mathrm{nm}^{2} / \text { molecule) }\right.\end{array}$ & 0.35 & 0.38 & 0.44 & 0.46 & 0.47 & 0.48 & 0.51 & 0.5 \\
\hline$\pi_{\mathrm{LE}-\mathrm{LC} 1}\left(\mathrm{mNm}^{-1}\right)$ & & & 1.5 & 4 & 7 & 10.5 & 14 & \\
\hline$\pi_{\mathrm{LC} 1-\mathrm{LC} 2}\left(\mathrm{mNm}^{-1}\right)$ & 26 & 22 & 18.5 & 14 & & & & \\
\hline $\begin{array}{l}\text { Collapse } \quad \text { pressure } \\
\left(\mathrm{mNm}^{-1}\right)\end{array}$ & 30 & 29 & 30 & 31 & 30 & 30 & 29 & 32 \\
\hline
\end{tabular}

Table 1. Values of molecular area of lift-off and surface pressures of LE-LC1 and LC1-LC2 transition plateau measured on the $\pi$-A isotherms. 


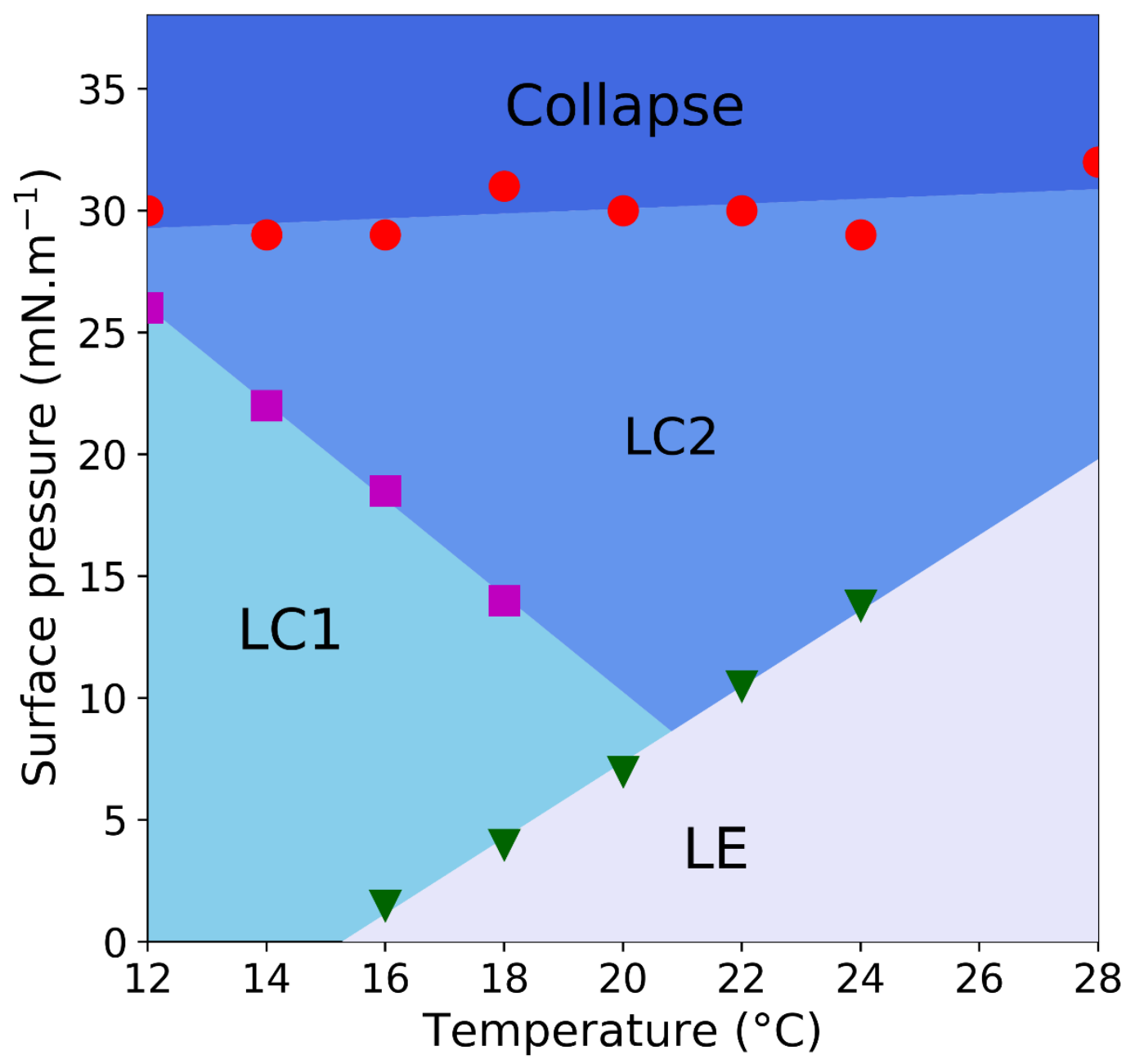

Figure 2. $\pi$-T phase diagram of $13-4 \mathrm{OH}$ film at the air-water interface. Dot, square and inverted triangle are the surface pressure values of the collapse, LC1-LC2 and LE-LC transitions respectively (deduced from the isotherms). The nature of the LC phases is determined by GIXD. Straight lines are guides for the eyes. 

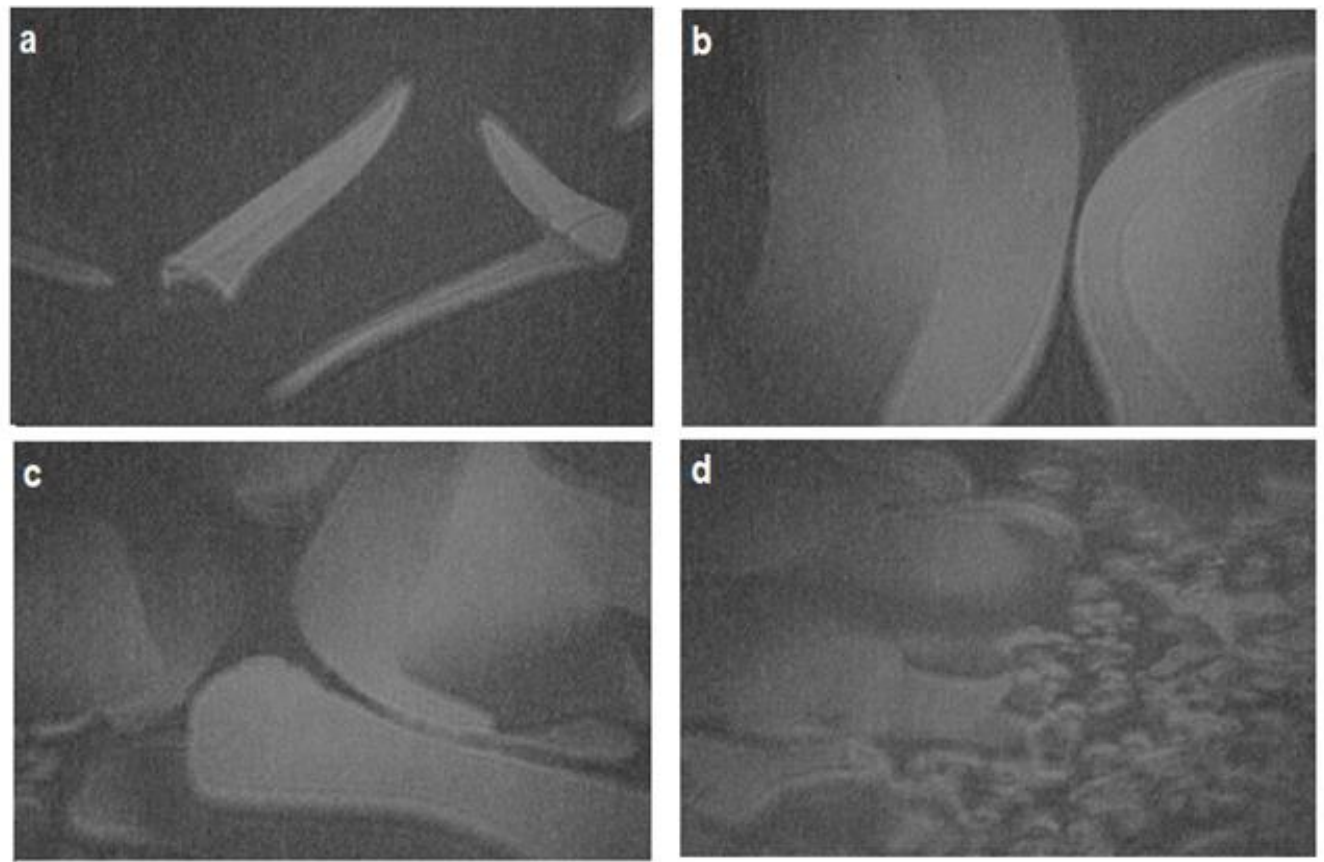

Figure 3. BAM images when compressing $13-4 \mathrm{OH}$ monolayer at $\mathrm{T}=13^{\circ} \mathrm{C}$. a) $\pi=2.4 \mathrm{mNm}^{-1}$, b) $\pi=4.7 \mathrm{mNm}^{-1}$, c) $\pi=15 \mathrm{mNm}^{-1}$ and d) $\pi=24 \mathrm{mNm}^{-1}$. Figures a, $\mathrm{b}$ and c correspond to the LC1 phase and d to the LC1-LC2 transition. The image size is $425 \times 350 \mu \mathrm{m}^{2}$. All images are obtained on the same sample. 


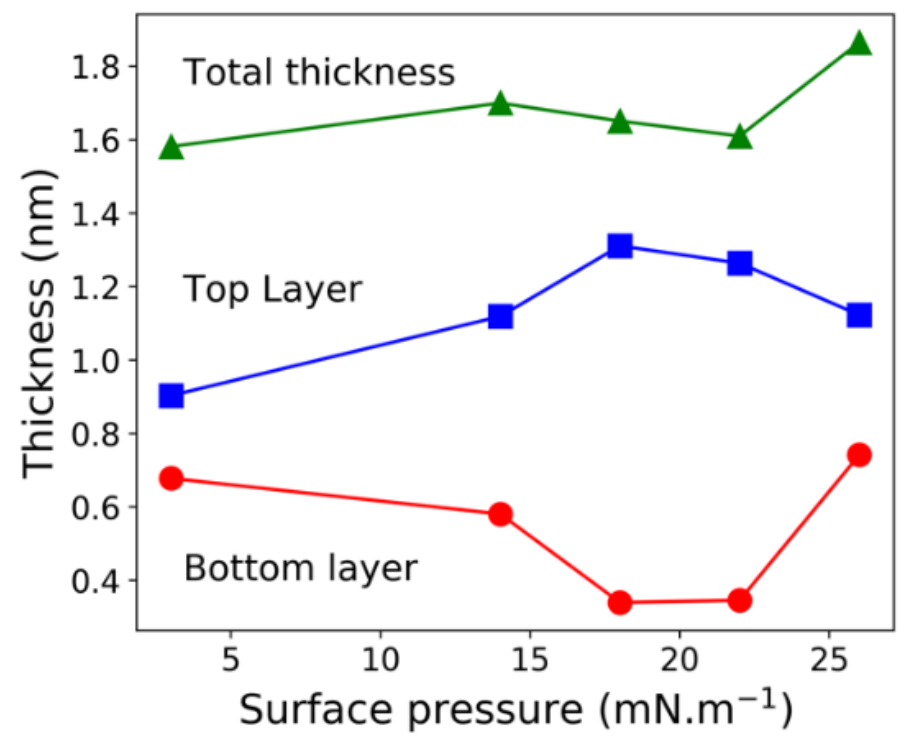

Figure 4: Thickness of each layer and total thickness versus surface pressure $\pi$ at $\mathrm{T}=14^{\circ} \mathrm{C}$, deduced from the adjustment of the reflectivity spectra with a two layers' model (data reported from Table 2). Bottom layer and top layer are the one in contact with the water subphase and the one in contact with the air respectively.

\begin{tabular}{|c|c|c|c|c|c|c|}
\hline $\begin{array}{c}\text { surface } \\
\text { pressure } \\
\left(\mathrm{mNm}^{-1}\right)\end{array}$ & $\begin{array}{c}\text { bottom } \\
\text { layer } \\
\text { density } \\
\left(\text { unit/ } / \AA^{3}\right)\end{array}$ & $\begin{array}{c}\text { bottom layer } \\
\text { thickness } \\
(\mathrm{nm})\end{array}$ & $\begin{array}{c}\text { bottom layer } \\
\text { roughness } \\
(\mathrm{nm})\end{array}$ & $\begin{array}{c}\text { top layer } \\
\text { density } \\
(\text { unit/令 }\end{array}$ & $\begin{array}{c}\text { top layer } \\
\text { thickness } \\
(\mathrm{nm})\end{array}$ & $\begin{array}{c}\text { top layer } \\
\text { roughness } \\
(\mathrm{nm})\end{array}$ \\
\hline $3(\mathrm{LC} 1)$ & 0.0044 & 0.678 & 0.225 & 0.0030 & 0.9035 & 0.304 \\
\hline $14(\mathrm{LC} 1)$ & 0.0048 & 0.581 & 0.609 & 0.0030 & 1.119 & 0.303 \\
\hline $18(\mathrm{LC} 1)$ & 0.0048 & 0.34 & 0.397 & 0.0030 & 1.311 & 0.323 \\
\hline $22(\mathrm{LC} 2)$ & 0.0048 & 0.346 & 0.238 & 0.0030 & 1.264 & 0.36 \\
\hline $26(\mathrm{LC} 2)$ & 0.0044 & 0.742 & 0.302 & 0.0030 & 1.123 & 0.343 \\
\hline
\end{tabular}

Table 2: Reflectivity parameters at $\mathrm{T}=14^{\circ} \mathrm{C}$ 

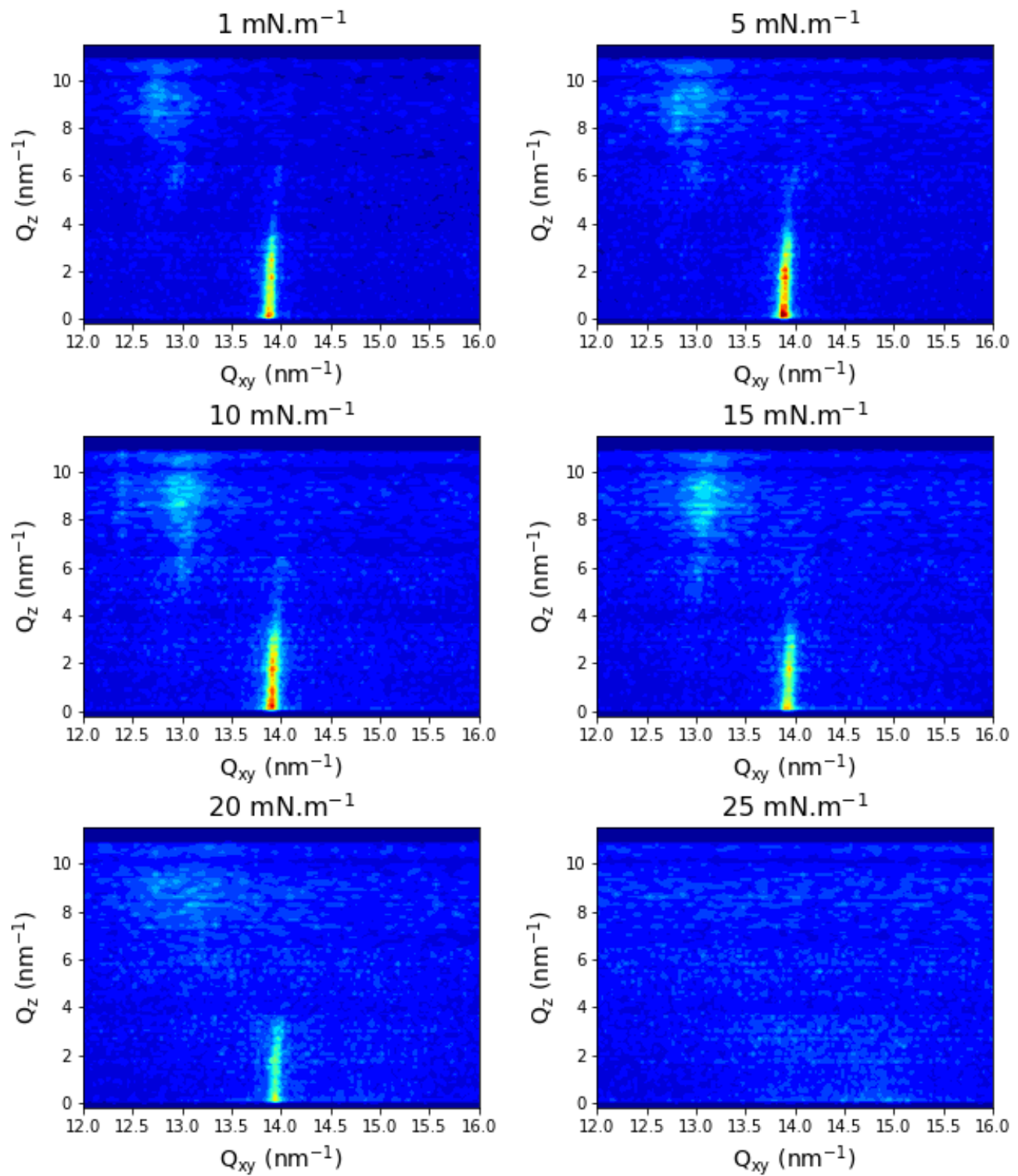

Figure 5. Grazing incidence $X$-ray diffraction spectra: $Q_{x y}-Q_{z}$ intensity maps for $13-4 O H$ monolayer at $\mathrm{T}=12^{\circ} \mathrm{C}$ at different surface pressures $\pi=1,5,10,15,20$ and $25 \mathrm{mNm}^{-1}$. 


\begin{tabular}{|c|c|c|c|c|c|c|}
\hline $\begin{array}{c}\text { Pressure } \\
\left(\mathrm{mNm}^{-1}\right)\end{array}$ & $\begin{array}{c}\mathrm{Q}_{\mathrm{xy}}[0,2] \\
\left(\mathrm{nm}^{-1}\right)\end{array}$ & $\begin{array}{c}\xi[0,2] \\
(\mathrm{nm})\end{array}$ & $\begin{array}{c}\mathrm{Q}_{\mathrm{xy}}[-1,1]+[1,-1] \\
\left(\mathrm{nm}^{-1}\right)\end{array}$ & $\begin{array}{c}\xi[-1,1]+[1,-1] \\
(\mathrm{nm})\end{array}$ & $\begin{array}{c}\mathrm{Q}_{z}[0,2] \\
\left(\mathrm{nm}^{-1}\right)\end{array}$ & $\begin{array}{c}\mathrm{Q}_{z}[-1,1]+[1,-1] \\
\left(\mathrm{nm}^{-1}\right)\end{array}$ \\
\hline 1 & 13.90 & 22.5 & 12.82 & 3.2 & 0 & 9.32 \\
\hline 5 & 13.90 & 21.8 & 12.95 & 3.2 & 0 & 8.93 \\
\hline 10 & 13.92 & 17.5 & 13 & 3.6 & 0 & 8.8 \\
\hline 15 & 13.94 & 16.5 & 13.1 & 4.0 & 0 & 8.59 \\
\hline 20 & 13.95 & 13.7 & 13.22 & 1.2 & 0 & 8.46 \\
\hline
\end{tabular}

Table 3: Peak positions $\mathrm{Q}_{\mathrm{xy}}\left(\mathrm{nm}^{-1}\right)$ and coherence lengths $\xi(\mathrm{nm})$ for pressures below the LC1LC2 order-disorder transition at $\mathrm{T}=12^{\circ} \mathrm{C}$. 


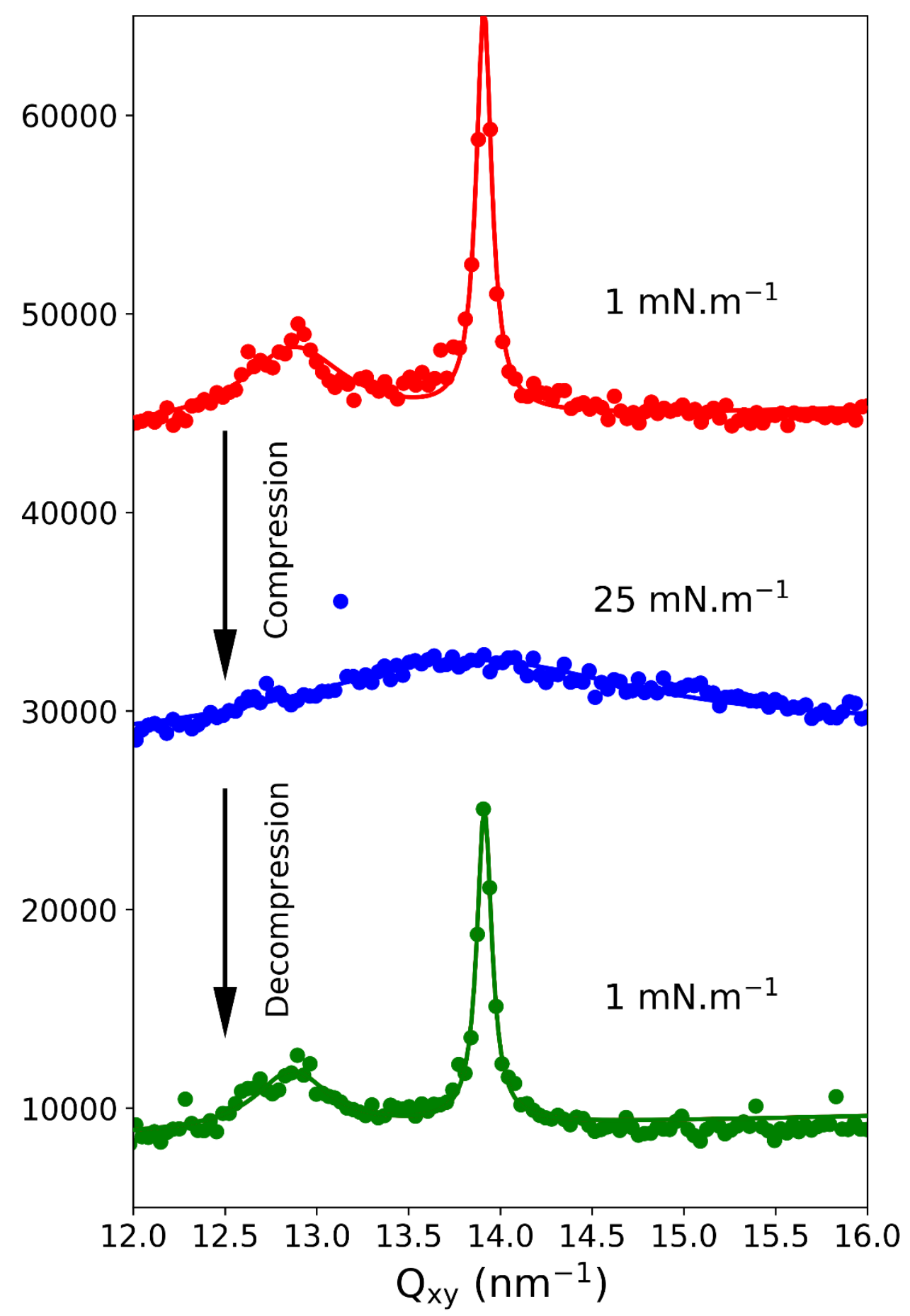

Figure 6. $\mathrm{Q}_{z}$ integrated GIXD spectra of $13-4 \mathrm{OH}$ monolayer at $12^{\circ} \mathrm{C}$ : up to bottom: $\pi=1 \mathrm{mNm}^{-1}$ in compression, $\pi=25 \mathrm{mNm}^{-1}$ and $\pi=1 \mathrm{mNm}^{-1}$ in decompression. 
- ASSOCIATED CONTENT

\section{Supporting Information.}

The unique file contains 6 items: $1.13-4 \mathrm{OH}$ isotherms, 2 . Enthalpy, 3 . Reflectivity at $\mathrm{T}=14^{\circ} \mathrm{C}$, 4. 13-4OH integrated intensity along $\mathrm{Q}_{z}$ at $\mathrm{T}=12^{\circ} \mathrm{C}$, 5. Simulation and 6 Equivalent acid DA: 13$3 \mathrm{COOH}$ phase diagram

- AUTHOR INFORMATION

\section{Corresponding Author}

Michel Goldmann - Sorbonne Université, CNRS-UMR 7588, Institut des NanoSciences de Paris, F-75005 Paris, France; Synchrotron SOLEIL, BP 48, Saint-Aubin 91192, Gif sur Yvette, France; UFR des Sciences Fondamentales et Biomédicales, Université de Paris, 75006 Paris, France.

Email : michel.goldmann@insp.jussieu.fr

\section{Author Contributions}

The manuscript was written through contributions of all authors. All authors have given approval to the final version of the manuscript.

\section{Notes}

The authors declare no competing financial interest. 


\section{- ACKNOWLEDGMENT}

We acknowledge DESY (Hamburg, Germany), a member of the Helmholtz Association HGF, for the provision of the use of synchrotron PETRA III, and acknowledge the grants Verbundforschung BMBF /05KS7FK3 /05KS10FK2 /05K16FK1 for funding the LISA instrument and the Lambda GaAs detector. We acknowledge Synchrotron SOLEIL (France) for synchrotron beam-time provision.

\section{- REFERENCES}

(1) (a) Reppy, M. A.; Pindzola, B. A. Biosensing with polydiacetylene materials: structures, optical properties and applications. Chem. Commun. 2007, $4317-4338$.

https://doi.org/10.1039/B703691D

(b) Weston, M.; Kuchel, R. P.; Ciftci, M.; Boyer, C.; Chandrawati, R. A. Polydiacetylene-based colorimetric sensor as an active use-by date indicator for milk. Journal of Colloid and Interface Science, 2020, 572, 31-38. https://doi.org/10.1016/j.jcis.2020.03.040

(2) Charych, D. H.; Nagy, J. O.; Spevak, W.; Bednarski, M. D. Direct colorimetric detection of a receptor- ligand interaction by a polymerized bilayer assembly. Science, 1993, 261, $585-588$. DOI: $10.1126 /$ science. 8342021

(3) (a) Fang, F.; Meng, F.; Luo, L. Recent advances on polydiacetylene-based smart materials for biomedical applications. Mater. Chem. Front., 2020, 4, 1089 - 1104.

https://doi.org/10.1039/C9QM00788A 
(b) Chen, X.; Zhou, G.; Peng, X.; Yoon, J. Biosensors and chemosensors based on the optical responses of polydiacetylenes. Chem. Soc. Rev., 2012, 41, $4610 \quad-\quad 4630$. https://doi.org/10.1039/C2CS35055F

(4) Kaganer, V. M.; Mohwald, H.; Dutta, P. Structure and phase transitions in Langmuir monolayers. Rev. Mod. Phys., 1999, 71, 779-819. https://doi.org/10.1103/RevModPhys.71.779

(5) Peterson, I. R.; Brzezinski, V. Equivalent states of amphiphilic lamellae. Langmuir, 1992, 8, 2995-3002.

(6) Lifshitz, Y.; Golan, Y.; Konovalov, O.; Berman, A. Structural Transitions in Polydiacetylene Langmuir Films. Langmuir, 2009, 25, 4469-4477. https://doi.org/10.1021/la8029038

(7) Gourier, C.; Knobler, C. M.; Daillant, J. ; Chatenay, D. Collapse of Monolayers of 10,12pentacosadiyonic acide: kinetics and structure. Langmuir, 2002, 18, 9434-9440. https://doi.org/10.1021/la026135v.

(8) Montierth, J. M.; DeMario, D. R.; Kurth, M. J.; Schore, N. E. The Polymer-Supported CadiotChodkiewicz Coupling of Acetylenes to Produce Unsynunetrical Diynes. Tetrahedron, 1998, 54, 11741-11748. https://doi.org/10.1016/S0040-4020(98)83035-4

(9) Aida, T.; Tajima, K. Photoluminescent Silicate Microsticks Containing Aligned Nanodomains Conjugated Polymers by Sol-Gel-Based In Situ Polymerization. Angew. Chem. Int. Ed., 2001, 40, 3803-3806.

https://doi.org/10.1002/1521-3773(20011015)40:20<3803::AID ANIE3803>3.0.CO;2-T 
(10) Murphy, B. M.; Greve, M.; Runge, B.; Koops, C. T.; Elsen, A.; Stettner, J.; Seeck, O. H.; Magnussen, O. M. A novel X-ray diffractometer for studies of liquid-liquid interfaces. $J$. Synchrotron Rad., 2014, 21, 45-56. https://doi.org/10.1107/S1600577513026192

(11) Seeck, O. H.; Deiter, C.; Pflaum, K.; Bertam, F.; Beerlink, A.; Franz, H.; Horbach, J.; Schulte-Schrepping, H.; Murphy, B. M.; Greve, M.; Magnussen, O. The high-resolution diffraction beamline P08 at PETRA III'. J. Synchrotron Rad., 2012, 19, 30-38.

https://doi.org/10.1107/S0909049511047236

(12) Björck, M.; Andersson, G. GenX: an extensible X-ray reflectivity refinement program utilizing differential evolution. J. Appl. Cryst., 2007, 40, 1174-1178.

https://doi:10.1107/S0021889807045086

(13) Fontaine, P.; Ciatto, G.; Aubert, N.; Goldmann, M. Soft Interfaces and Resonant Investigation on Undulator Source: A Surface X-ray Scattering Beamline to Study Organic Molecular Films at the SOLEIL Synchrotron. Sci. Adv. Mater., 2014, 6, 2312-2316. https://doi.org/10.1166/sam.2014.2189

(14) Als-Nielsen, J.; Mohwald, H. in Handbook of Synchrotron Radiation, ed. S. Ebashi, M. Koch and E. Rubenstein, Elsevier Science, Amsterdam, 1991, ch. 1, vol. 4, p. 1.

(15) Plimpton, S.; Fast Parallel Algorithms for Short-Range Molecular Dynamics. J. Comput. Phys., 1995, 117, 1-19. https://doi.org/10.1006/jcph.1995.1039

(16) Berendsen, H. J. C.; Grigera, J. R.; Straatsma, T. P. The missing term in effective pair potentials. Journal of Physical Chemistry, 1987, 91, 6269-6271. 
(17) Kusalik, P. G.; Svishchev, I. M. The spatial structure in liquid water. Science, 1994, 265, 1219-1221. DOI: 10.1126/science.265.5176.1219

(18) Jorgensen, W. L.; Maxwell, D. S.; Tirado-Rives, J. Development and Testing of the OPLS All-Atom Force Fieldon Conformational Energetics and Properties of Organic Liquids. J. Am. Chem. Soc., 1996, 118, 11225-11236. https://doi.org/10.1021/ja9621760

(19) Yu, Z.W.; Jin, J.; Cao, Y. Characterization of the liquid-expanded to liquid-condensed phase transition of monolayers by means of compressibility. Langmuir 2002, 18, 4530-4531.

(20) Fradin, C.; Daillant, J.; Braslau, A.: Luzet, D.; M. Alba, Goldmann, M. -Microscopic measurement of the linear compressibilities of two-dimensional fatty acid mesophases. Eur. Phys. J. B 1998, 1, 57-69. https://doi.org/10.1007/s100510050152

(21) Bourdieu, L.; Chatenay, D.; Daillant, J.; Luzet, D. Polymerization of a diacetylenic phospholipid monolayer at the air-water interface. J. Phys.II France, 1994, 4, 37-58. https://doi.org/10.1051/jp2:1994114

(22) Majewski, J.; Popovitz-Biro, R.; Bouwman, W. G.; Kjaer, K.; Als-Nielsen, J.; Lahav, M.; Leiserowitz, L. The Structural Properties of Uncompressed Crystalline Monolayers of Alcohols $\mathrm{C}_{\mathrm{n}} \mathrm{H}_{2 \mathrm{n}+1} \mathrm{OH}(\mathrm{n}=13-31)$ on Water and Their Role as Ice Nucleators. Chem. Eur. J., 1995, I, 304-311. https://doi.org/10.1002/chem.19950010507

(23) Popovitz-Biro, R.; Wang, J. L.; Majewski, J.; Shavit, E.; Leiserowitz, L.; Lahav. M. Induced Freezing of Supercooled Water into Ice by Self-Assembled Crystalline Monolayers of Amphiphilic Alcohols at the Air-Water Interface. J. Am. Chem. Soc., 1994, 116, 1179-1191. 
(24) Hoang, V. D.; Tran, H. H.; Phuong, C. C.; Nguyen, H. M. T.; Nguyen, T. T. Investigating molecular mechanism for the stability of ternary systems containing cetrimide, fatty alcohol and water by using computer simulation. Cond. Mat. Soft. 2019, 1-10.

(25) Yue, X.; Dobner, B.; Iimura, K.; Kato, T.; Mohwald, H.; Brezesinski, G. Weak First-Order Tilting Transition in Monolayers of Mono- and Bipolar Docosanol Derivatives. J. Phys. Chem. B, 2006, 110, 22237 - 22244. https://doi.org/10.1021/jp056482o

(26) Shimizu, M.; Yoshida, M.; Iimura, K.; Suzuki, N.; Kato, T. Area-temperature (A-T) isobars of monolayers of octadecylureas at the air/water interface. Colloids and Surfaces SURFACES A: Physicochemical and Engineering Aspects, 1995, 102, 69-73. https://doi.org/10.1016/09277757(95)03240-E

(27) Du, Q.; Superfine, R.; Freysz, E.; Shen, Y. R. Vibrational Spectroscopy of Water at the Vapor/Water Interface. Physical Review Letters, 1993, 70, 2313-2316. https://doi.org/10.1103/PhysRevLett.70.2313 
For Table of contents only

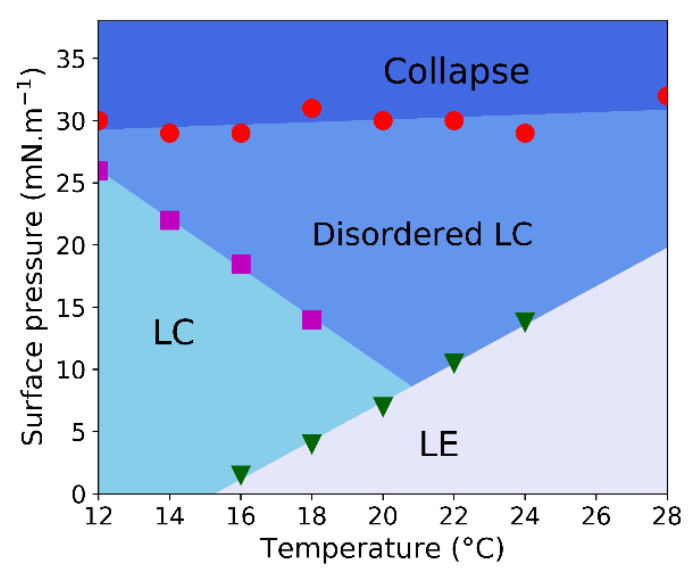

Disordered LC

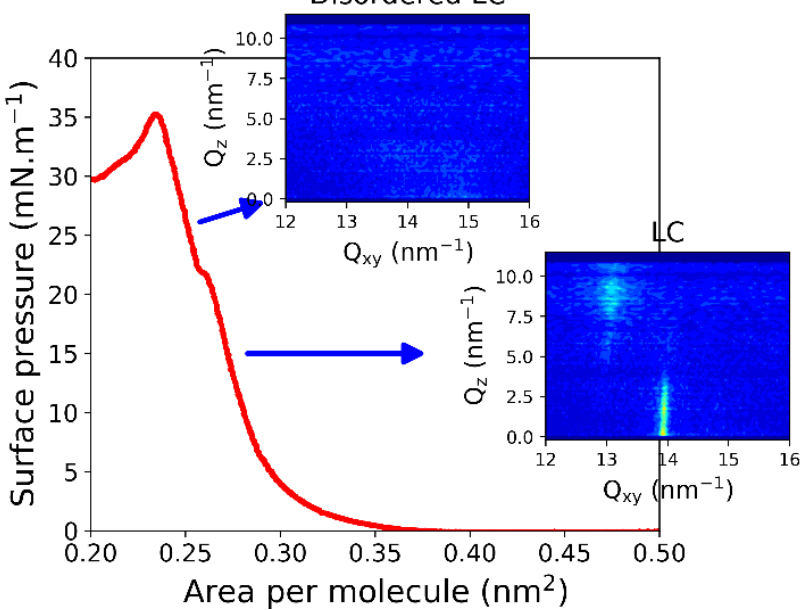

